\title{
Development of a postural support device for cross- table radiography of the extremities
}

\section{N Ebrahim Nat Dip Rad (Diag), FETC (London), MSc Radiography (Diag) (UK) \\ Department of Radiography Medical University of Southern Africa}

\section{Introduction}

A postural support device ${ }^{*} \mathrm{RSA}$ Registered Design Application No. F2002/0033) was originally developed to provide immobilisation for patients requiring cross-table radiography of the hip joint. On further investigation it was found that it had additional applications, as discussed later.

\section{Background}

The routine projections for fractures or dislocations of the hip joint include the antero-posterior projection of the pelvis and the cross-table

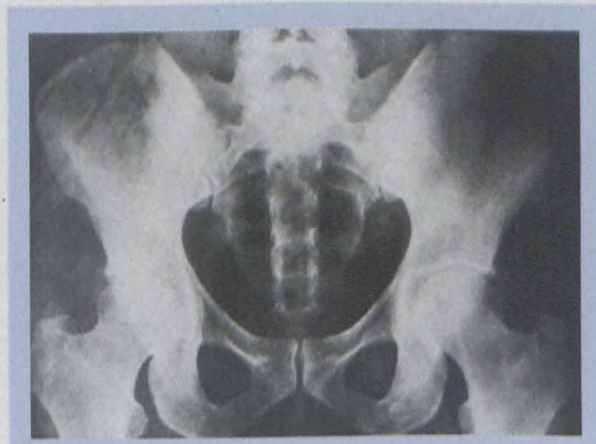

Fig. 1a. Supine pelvis.

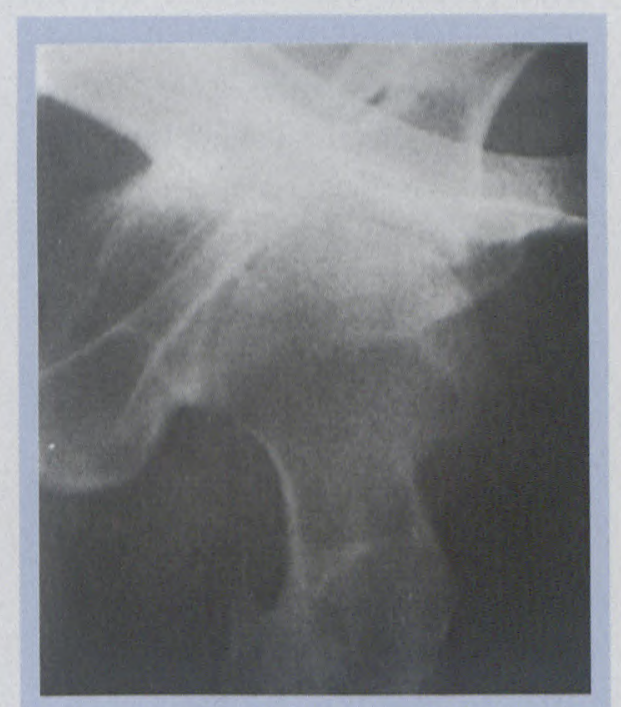

Fig. 1b. Cross-table lateral of the hip joint demonstrating the femoral neck.

lateral projection of the neck of the femur (Figs la and lb).

In order to demonstrate the neck of the femur, the unaffected leg has to be raised and supported. Radiographers have traditionally used a chair, stacks of soft pads, an individ- ual, or the X-ray tube to support their patients.

In 1998 a national survey, utilising self-completing questionnaires was conducted amongst 54 radiographers working in public and private hospitals. Respondents were required inter alia to indicate the type of support that they were using, the categories of patients seen, what the repeat rate was and whether they thought their method of support was safe. This survey contributed to a needs analysis for consideration of marketing the device.

\section{Results}

Forty-one (79.5\%) of the 54 questionnaires were returned. They were statistically analysed and revealed the following information (Tables I - IV).

From the above results it can be seen that a large percentage of adults required radiography of the hip joint. One practice had a specially designed support but it was not height adjustable. Whilst $56.1 \%$ of respondents did not have to repeat the radi-

\begin{tabular}{|lc|}
\hline \multicolumn{2}{|c|}{$\begin{array}{c}\text { Table I. Patients most often/equally } \\
\text { seen }(\text { rating }=1)\end{array}$} \\
\hline Category & Percentage \\
\hline Geriatrics & 63.4 \\
Adults & 56.1 \\
Juveniles & 10.5 \\
Infants & 15.8 \\
\hline
\end{tabular}

\begin{tabular}{|lcc|}
\hline \multicolumn{3}{c|}{ Table II. Method of support (combined figures) } \\
\hline Support & Number & Percentage \\
\hline Box & 14 & 34.1 \\
Chair & 9 & 21.9 \\
X-ray tube & 22 & 53.7 \\
Assistant & 18 & 43.9 \\
Specially designed support & $1^{*}$ & 2.4 \\
* Not height adjustable. & & \\
\hline
\end{tabular}




\begin{tabular}{|lc|}
\hline \multicolumn{2}{|c|}{$\begin{array}{c}\text { Table III. } \\
\text { Repeat radiographs due to } \\
\text { poor support }\end{array}$} \\
\hline Response & Percentage \\
\hline Yes & 43.9 \\
No & 56.1 \\
\hline
\end{tabular}

\begin{tabular}{lc}
\multicolumn{2}{c|}{$\begin{array}{c}\text { Table IV. Is your current support } \\
\text { safe? }\end{array}$} \\
\hline Response & Percentage \\
\hline Yes & 28.6 \\
No & 71.4 \\
\hline
\end{tabular}

ographic projection, $71.4 \%$ of the respondents did not regard their current support as being safe.

\section{Current problems}

A chair is: (i) cumbersome; (ii) not height adjustable in most cases; and (iii) difficult to place outside the area of interest.

The leg on the X-ray tube means that: $(i)$ the patient feels insecure; (ii) the leg has to be shifted several times when the height of the X-ray tube is adjusted - patients may not be wearing shoes and may sustain a burn to the heel; and (iii) the foot is exposed to radiation due to its close proximity to the exiting beam.

An assistant has: (i) unnecessary exposure to radiation; (ii) back strain; and (iii) difficulty experienced in immobilisation.

\section{Repeat radiographs}

The major contributing factors for repeat radiographs are as follows: (i) superimposition of the soft tissues of the unaffected limb on the structure being demonstrated; and (ii) motional unsharpness due to discomfort experienced by the patient.

\section{Solution}

During 1996 the idea of a leg support was disclosed to the Research and Ethics Committee of the Medical University of Southern Africa. The prototype was designed in 1997. The device was tested at Ga-Rankuwa Hospital's X-ray department. The management of the university also recommended that an application for a design protection be lodged. The final product was manufactured in 2002 (Figs $2 a$ and $2 b$ ). Fig. 3 illustrates the application of the device during cross-table lateral radiography of the hip joint. The device may also be used during cross-table radiography of the lower limb (Fig. 4), and cross-table radiography of the shoulder (Fig. 5).

\section{Versatility}

Orthotists, prosthetists, occupational therapists, orthopaedic surgeons and plastic surgeons can also

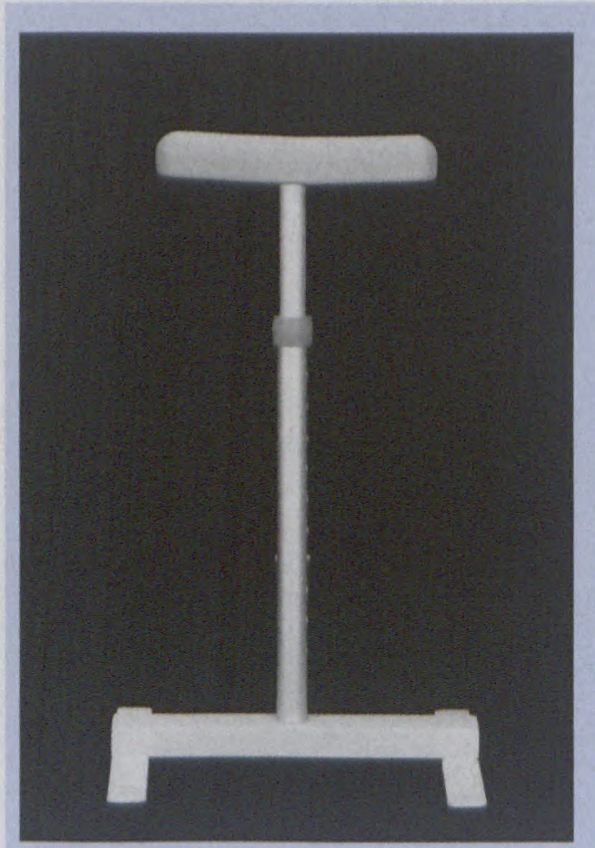

Fig. 2a. Elevation view of the postural support device.

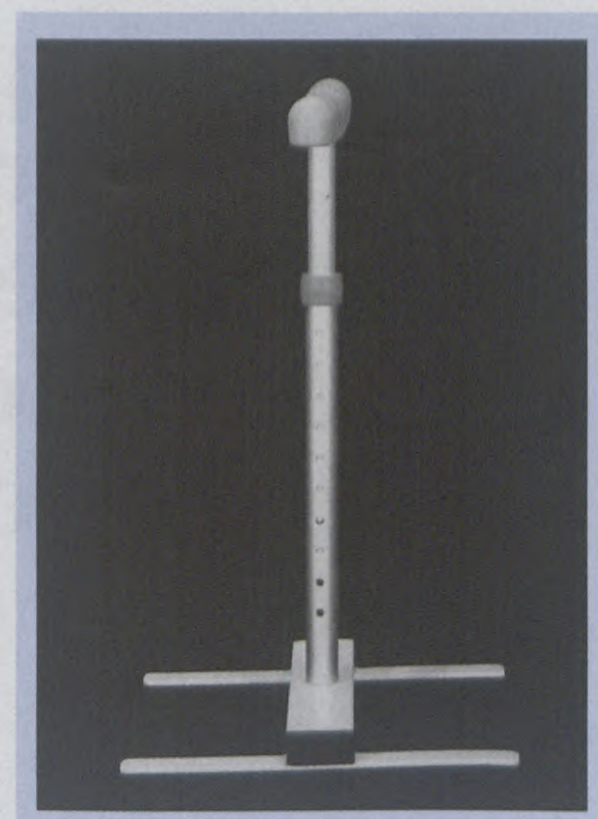

Fig. $2 b$. Side view of the postural support device. Note: The device is: lightweight $(1.5 \mathrm{~kg})$, height adjustable $(43-66 \mathrm{~cm})$, portable, safe and aesthetically attractive.

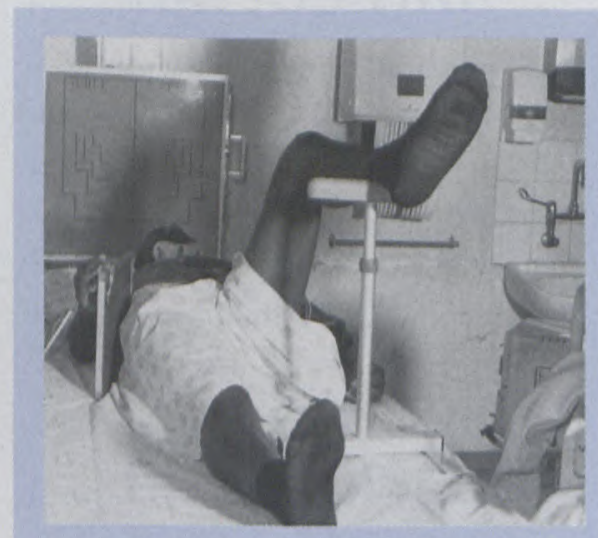

Fig. 3. Positioning for cross-table lateral radiography of the hip joint using the postural support device.

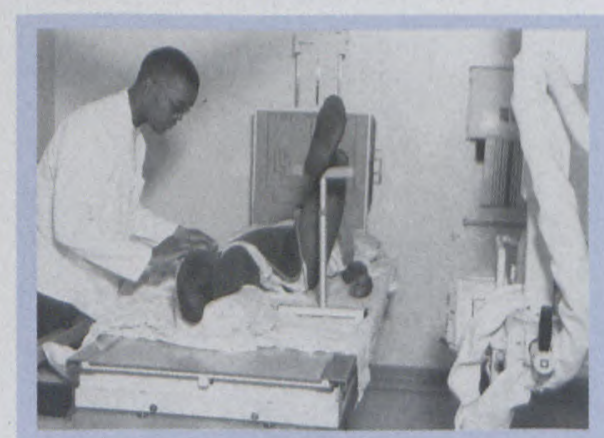

Fig. 4. Positioning for cross-table lateral radiography of the lower leg. 


\section{SHORT REPORT}

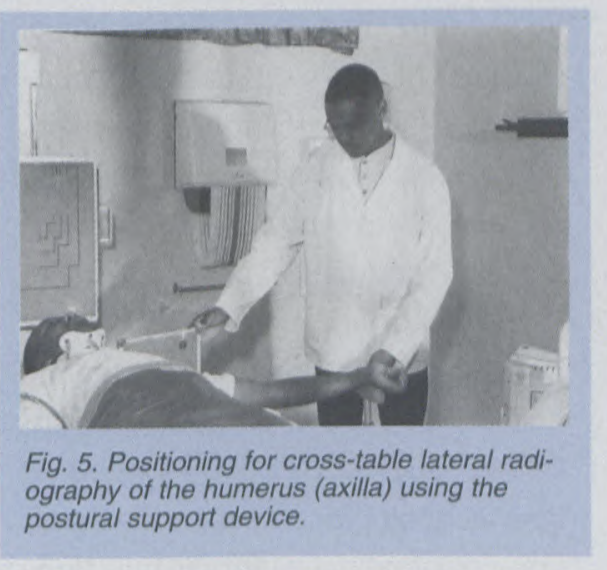

use the device when fitting appliances, traction or dressings.

\section{Outcomes}

The application for design protection through the Medical University of Southern Africa resulted in: (i) the compilation and institution of an Intellectual Property Policy at the Medical University of Southern Africa; and (ii) the submission of a Portfolio of Evidence entitled 'Intellectual Property - An Inventor's Perspective' as partial fulfilment of a MSc in Diagnostic Radiography offered by the Anglia Polytechnic University, Cambridge, United Kingdom.

I would like to thank the management of the Medical University of Southern Africa for their support, Professor H S Schoeman for his assistance with the statistical analysis, $\mathrm{Mr} \mathrm{J}$ Van Loggenberg for the manufacture of the prototype, Mr Grant Pywell of ASG Medical Equipment Services for his assistance in developing the device, Mr Mike Von Seidel for his assistance in the application for Design Protection, the management of the X-ray Department Ga-Rankuwa Hospital for allowing the trials to be conducted and the student radiographers who assisted with the photography of the device. My thanks also go to the following departments at the Medical University of Southern Africa: the Department of Medical Illustration and Audio-Visual Services, the Department of Occupational Therapy and the Department of Orthopaedics for their assistance in the development and application of the product.

\section{Primary Care Radiology}

\section{F A Mettler, Jr, Milton J Guiberteau, Carolyn M Voss \& C E Urbina}

Here's a practical resource designed to help practitioners select appropriate radiologic tests for a full range of common disorders. From simple x-rays to sophisticated imaging studies, this clinical reference examines virtually every procedure in use today. It's organized by anatomic system, with a focus on symptoms and suspected clinical problems, to make reference simple. This valuable tool helps readers order even the most expensive and complex radiologic studies with confidence.

\section{Features}

$\Rightarrow$ Examines the pros and cons of a broad spectrum of imaging studies, including their diagnostic value and their cost effectiveness.

$\Rightarrow$ Addresses when a study should or should not be ordered, and the proper sequence in which radiologic tests should be performed for specific symptoms or suspected disorders.

$\Rightarrow$ Offers full coverage of common inpatient and outpatient conditions, such as chest pain, asthma, diabetes, and back pain.

$\Rightarrow$ Describes both adult and pediatric conditions.

$\Rightarrow$ Illustrates normal anatomy, normal variants, and common diseases and disorders with more than 300 clearly reproduced illustrations.

$\Rightarrow$ Includes step-by-step guidance on the interpretation of x-ray images.

$\Rightarrow$ Considers common pitfalls and how to avoid them.

$\Rightarrow$ Highlights vital information with quick reference tables.

$\Rightarrow$ Integrates the perspectives and experience of two radiologists, a general medical internist, and a family practice physician.

May 2000, paperback, 285 pp, 340 illustrations, WBS, R799

Orders: SA Medical Association, Private Bag X1, Pinelands 7430. Tel (021) 530-6527.

Fax (021) 531-4126. E-mail: fpalm@samedical.org Limited local stock. 